\title{
Pastoral urbana: o "ver" decolonial de Jesus
}

\author{
Urban pastoral: Jesus' decolonial view
}

\author{
Carlos Alberto Motta Cunha (ida \\ JUNIOR VASCONCELOS DO AMARAL ${ }^{b}$
}

\section{Resumo}

Como o ministério de Jesus Cristo, descrito nos Evangelhos, pode inspirar e desafiar a teologia pastoral de hoje? O presente artigo busca respostas inconclusas à esta questão, apontando para uma pastoral cristã no contexto urbano contemporâneo. O mundo da cidade, dinâmico e plural, interpela a prática pastoral capaz de "ver" com profundidade os seus dilemas e dar uma palavra prática e libertadora às pessoas que lutam pela sobrevivência. Inspirados pelo caminho do próprio Cristo, oferecemos uma análise exegética de pequenas narrativas do "ver de Jesus" à luz do pensamento decolonial como provocações para a pastoral urbana. Sem medo de cair em anacronismos, constatamos a importância dos feitos subversivos de Jesus em romper as amarras colonialistas e promover a decolonialidade dos corpos e das convicções.

Palavras-chave: Pastoral urbana. Práxis cristã. Pensamento decolonial.

\begin{abstract}
How can the ministry of Jesus Christ, as described in the Gospels, inspire and challenge pastoral theology today? This article seeks to find open answers to this question by focusing on Christian pastoral care in a contemporary urban context. The dynamic and pluralistic world of the city challenges pastoral practice that must be able to attentively "see" its dilemmas and give a practical and liberating response to those who struggle for survival. Inspired by the path of Christ himself, we provide an exegetical analysis of some small narratives of "seeing Jesus" in the light of decolonial thinking as provocations for urban

\footnotetext{
a Universidade Católica de Minas Gerais (PUC Minas), Belo Horizonte, Minas Gerais, Brasil. Doutor em Teologia, e-mail: carlosamc04@.gmail.com

b Pontifícia Universidade Católica de Minas Gerais (PUC Minas), Belo Horizonte, Minas Gerais, Brasil. Doutor em Teologia, e-mail: jvsamaral@yahoo.com.br
} 
pastoral care. Without fearing to fall into anachronisms, we have observed the importance of Jesus' subversive deeds when breaking the bonds of colonialism and promoting the decoloniality of bodies and convictions.

Keywords: Urban pastoral. Christian praxis. Decolonial thinking.

\section{Introdução}

No Ortodoxia subversiva, Robert Inchausti, descrevendo a riqueza inquietante do pensamento de William Blake, lembra a importância da "visão" na aquisição do conhecimento da nossa condição ontológica de criaturas feitas à imagem de Deus. Segundo ele, fazendo referência a Blake, "visão, em sua forma mais concentrada e inclusiva, é o que os psicanalistas chamam de 'imago', uma imagem interna que transforma fatos em significados" (INCHAUSTI, 2021, p. 29-30).

Resgatar a visão de Jesus por meio da expressão "ver as multidões", narrada nos Evangelhos pode ser uma contribuição importante para a pastoral urbana de hoje. Mais provocador ainda é associar ao "ver" de Jesus o pensamento decolonial, que vem sendo construído nas últimas décadas. Juntar teologia pastoral com a decolonialidade constitui transformar o evento Jesus Cristo em significado interpelante para o sentido e a prática da pastoral no contexto urbano de hoje. A teoria decolonial revela ainda mais as raízes libertadoras e anticolonialistas do discurso e dos feitos do Nazareno.

Quando falamos sobre decolonialidade ou teoria decolonial, estamos tratando de um pensamento que se movimenta no decorrer da história e vai, aos poucos, sendo sistematizado em teoria (conhecimento organizado). Desde que o indivíduo se entende como pessoa (ser em relação), há o afloramento da consciência das relações de dominação e subalternização. Tal consciência se evidencia diante das grandes transformações no mundo a partir dos séculos XVXVI e as ações de "descobrimento", ou melhor, "encobrimento" do outro. As reflexões da teoria decolonial se somam, de forma mais crítica, aos estudos subalternos, pós-estruturais, desconstrutivistas e pós-colonialistas críticos às concepções dominantes da modernidade e provocam outros saberes, inclusive à teologia pastoral. 
O nosso objetivo é fazer uma leitura decolonial da expressão "vendo ele as multidões" de Mateus 5,1, como foco em uma hermenêutica voltada à pastoral urbana. Como o ministério de Jesus, descrito nos Evangelhos, pode inspirar e desafiar a teologia pastoral de hoje, em um mundo urbano, globalizado, marcado por ações colonialistas? O "ver" decolonial do Galileu para as multidões empobrecidas e subalternizadas desinstala corpos, mentes e corações rumo a uma pastoral de reconhecimento do valor do outro. Atitudes de empatia e acolhimento fazem parte deste exercício.

$O$ texto se divide em quatro momentos, estes que orientam a nossa opção metodológica. No primeiro, analisamos o texto de Mateus 5,1 e suas consonâncias em Marcos para fundamentar, do ponto de vista exegético, a importância do "ver de Jesus as multidões" para a pastoral. No segundo e terceiro momento introduzimos algumas categorias do fazer decolonial: epistemologias do sul e giro decolonial', com a intenção de sublinhar o discurso subversivo e provocativo do Reino de Deus anunciado pelo Nazareno. No quarto e último momento, apontamos caminhos para uma pastoral urbana inspirada no "ver" de Jesus. Os desafios são colocados para uma pastoral "em saída" disposta a se refazer diante das demandas dos sujeitos urbanos do nosso tempo.

\section{Análise exegética de Mateus 5,1 e suas consonâncias em Marcos}

A práxis de Jesus nos Evangelhos está pautada pela compaixão e misericórdia. Um dos traços da misericórdia de Jesus se revela em seu olhar, em como ele é capaz de ver além das aparências, notando a essência do coração

\footnotetext{
1 O "Pensamento decolonial" está difuso em várias áreas do conhecimento e com muitas abordagens e categorias. Optamos pela linha teórico-prática do Grupo Modernidade/Colonialidade/Decolonialidade (Grupo M/C/D) - formado por intelectuais latinoamericanos e americanistas -, marcada pela necessidade de decolonizar a epistemologia e o cânone ocidentais. O Grupo M/C/D rompe parcialmente com a teorização dos grupos de estudos subalternos e avança para a crítica decolonial, que denuncia o eurocentrismo por parte dos saberes silenciados e subalternizados. Aníbal Quijano, Enrique Dussel, Walter Mignolo, Catherine Walsh, Nelson Maldonado-Torres, Boaventura de Sousa Santos e Maria Paula Meneses são alguns dos integrantes desta linha de pensamento. No leque da decolonialidade proposto por esses autores, "giro decolonial" (Maldonado-Torres, Dussel etc.) e "epistemologias do sul" (Sousa Santos, Meneses etc.) aparecem como categorias constitutivas do fazer decolonial.
} 
humano. Nos evangelhos, mesmo considerando a especificidade de cada um, há de modo geral a ocorrência de que Jesus conhecia o ser humano por dentro ou sabia o que ocorria em seus pensamentos ( $L C 5,22 ;$ Jo 2,25b). A leitura decolonial dos evangelhos evita extrair deles uma única imagem de Jesus Cristo. Pelo contrário, o evento Cristo, lido e interpretado pela ótica decolonial, acolhe a riqueza dos múltiplos olhares sobre os ditos e os feitos de Jesus. Neste sentido, compreende-se no ver de Jesus tanto a cristologia ascendente dos sinópticos como a cristologia descendente de João. O que se pode observar é a construção do personagem Jesus e a capacidade de seu olhar.

É possível encontrar nos Evangelhos Sinópticos dois verbos gregos que expressam o ato de olhar e ver, são os verbos blepo e 'oráo. A opção deste estudo é pelo verbo 'orao, no aoristo, eiden, que ocorre 42 vezes no Novo Testamento e que dá a entender o sentido de compreensão, de análise mais profunda da realidade ou de uma pessoa que esteja em sua direção. No caso deste trabalho será a multidão, uma categoria importante para o Evangelho de Mateus.

No que se refere ao verbo "ver", em Mateus 3,16, na cena do batismo de Jesus, se lê: kai eidén to pneuma, "e viu o Espírito" e, em 4,16, skótei fós eiden méga kai, "e na escuridão viu-se uma grande luz", versículo na perícope do início de seu ministério na Galileia. Nestas cenas, pode-se observar a dimensão espiritual na qual o verbo "ver" está inserido, tanto acerca da luz do batismo, como a grande luz que vem à escuridão, como Jesus que surge para anunciar a Boa Nova de Deus no mundo.

O verbo eiden pode ser encontrado primeiro em Marcos 1,16, eiden Simona kai Andréan ton adelfon Simonos, amfibállontas en te talásse, que se traduz por: "Viu Simão e André o irmão de Simão lançando a rede ao mar". Em seguida, no v. 19, Kai probás olígon eiden lakobon ton tou Zebedaíou kai loannen ton adelfon autou que se traduz por: "E avançando um pouco viu Tiago o filho de Zebedeu e João o irmão dele". Em terceiro momento, em Marcos 2,14: kai parágon eiden Levin ton tou Alfaióu [...], traduzido por: "E passando viu Levi o filho de Alfeu". Nestes três versículos, o verbo em destaque neste artigo tem conotação de conhecimento, de discernimento por parte de Jesus na escolha de seus primeiros discípulos no itinerário inicial do Evangelho marcano. Jesus olha, discerne quem são seus primeiros seguidores, aqueles que estarão com ele durante toda sua caminhada missionária. 
No grego de Mateus, em 4,18.21, no interior da perícope da vocação dos primeiros discípulos, encontramos também o verbo eiden, na mesma perspectiva do Evangelho de Marcos. Em sentido semântico, corresponde ao olhar de Jesus capacitado ao discernimento. Ele avalia seus discípulos no processo do seguimento, o discipulado. Destarte, pode-se considerar que a ação de ver, por parte de Jesus, é também avaliação do que deve fazer, neste caso, discernir sobre quem poderia segui-lo ou não pelo caminho.

Em Mateus 8,14 é possível encontrar o verbo eiden no cenário das curas protagonizadas por Jesus em sua taumaturgia. O texto grego diz: Kai eltón ó lesous eis tén oikían Petrou eiden ten penterán autou. Jesus chegou à casa de Pedro e viu a sogra dele deitada. Na perspectiva da cura, cenário comum tanto a Mateus quanto a Marcos, o olhar de Jesus é decisivo, de discernimento em relação aos que sofrem e a necessidade de ele ser compassivo e misericordioso, agindo com a mão de Deus e curando as pessoas.

No que diz respeito a Mateus 5,1 o verbo no aoristo, eiden, contém o mesmo significado dos contextos anteriores deste evangelho, possibilitando entender a capacidade de Jesus avaliar a realidade daqueles que o seguem e o escutam, que estão com ele e querem aprender dele. A ação de discernir, por parte de Jesus, permite perceber não apenas o conjunto de seus ouvintes e interlocutores, mas também aquilo que ele ensina, o conteúdo de sua didática.

Dignos de nota são os substantivos óxlon e óxlous, traduzidos por "multidão" ou "multidões", para as quais o olhar de Jesus se destina. Para este estudo é considerável fazer uma breve explanação de sua presença no versículo de Mateus 5,1 e sua consonância em Marcos.

Em Mateus 5,1, pode-se ler no grego idón dé tous óxlous anébe eis tó óros, traduzido literalmente por: "Tendo visto as multidões subiu para o monte”. Neste versículo, Mateus usa o termo multidão no plural. Em Marcos 6,34, é possível encontrar kai exeltón eiden polín óxlon kai esplagxniste ep autoús, que pode ser traduzido por: "E saindo viu grande multidão e compadeceu-se deles". O léxico grego oxlon, que ocorre neste versículo é um acusativo masculino singular, pode ser traduzido por "a multidão".

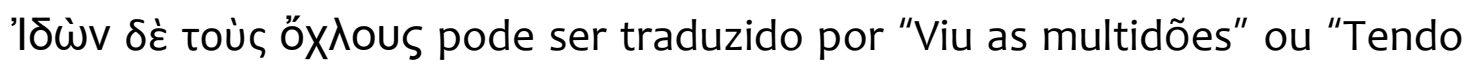
visto as multidões". O idón, no aoristo particípio ativo, ocorre 61 vezes em todo o 
Novo Testamento, podendo ser variavelmente traduzido por "viu", "vendo", "tendo visto" e ainda "conheceu". O substantivo nominativo (acusativo plural) óxlous, que corresponde às "multidões", ocorre 17 vezes no Novo Testamento, em sua maioria, 10 vezes, no Evangelho de Mateus. O capítulo 14 é o que mais concentra o termo óxlous, 4 vezes (14,15.19.22.23), trata-se da perícope em que Mateus narra a multiplicação dos pães, um milagre realizado para as multidões.

No Discurso do Monte, Mateus 5-7, também conhecido como discurso inaugural (JEREMIAS, 1976), encontra-se o cerne da didaskalia, dos ensinamentos, de Jesus. Jesus ensina com exousia, poder-autoridade e ao mesmo tempo ensina o que é fundamental, o essencial para aqueles que vão continuar a segui-lo, desde o chamado até sua morte e ressurreição, bem como depois do evento máximo da ressurreição, no tempo da Igreja. O ensinamento de Jesus vai além da transferência de conhecimento intelectual ou da sabedoria popular. Antes, o ensinamento de Jesus tem exousia porque é atestado pelo seu testemunho de vida (martyrio). Destarte, Jesus fala o que vive, testemunha o que prega. Diferentemente dos falsos religiosos de seu tempo, que em suas pregações, por exemplo, entravam nas casas das viúvas e lhes roubavam (Mc 12,40; Mt 23,14). Os discípulos de Jesus, portanto, ficam maravilhados com as palavras de seu mestre porque elas refletem a verdade de vida (Mt 8,28-29).

Pode-se depreender da abordagem exegética a importância do "ver" de Jesus, que se constitui ação discernente, que perscruta a realidade e a vida das pessoas. Pode-se dizer que ao "ver" Jesus realiza uma ação pastoral compreensiva e ao mesmo tempo personalizada, pois coloca em evidência a pessoa do outro. Este processo de discernimento pastoral por parte de Jesus se percebe em Marcos 1,16, como vimos anteriormente, no relato do chamado de Simão e André ao discipulado, no qual o narrador diz que Jesus "viu Simão e seu irmão André" eíden Símona kai Andréan, tón adelfón Símonos. O verbo no aoristo pode compreender uma visão mais compreensiva de Jesus, que está discernindo quem são as pessoas que devem segui-lo. Também em Marcos 1,19, logo em seguida, o narrador afirma: "Viu Tiago, o Filho de Zebedeu e João, seu irmão" em grego Eíden lákobon tón tou Zebedáion, kai loánnen, tón adelfón autou. Marcos repete o verbo ver, que significa o olhar compreensivo de Jesus no processo de construção de seu discipulado.

Voltando ao cenário de Mateus, encontramos nas Bem-aventuranças uma relação entre quem ensina e os ensinados. Jesus toca a vida de inúmeras pessoas 
daquele cenário, junto ao mar da Galileia. Para Theissen e Merz (THEISSEN; MERZ, 2004, p. 240), o poder de influência carismática de Jesus pode evidenciar que seu movimento ultrapassa as barreiras do círculo mais restrito de seguidores (discípulos) e atinge grupos maiores da população (multidão). A análise de Theissen e Merz nos ajuda a compreender o alcance da "visão" de Jesus, que acaba tocando a vida das pessoas, seja dos discípulos, seja das multidões.

No cenário de Mateus 5-7 o "ver de Jesus as multidões" implica a atitude do pastor que se preocupa com seu rebanho, pastor que tem os olhos fixos no rebanho, cuidando dele. Jesus vê as multidões como a seus próprios seguidores, embora não haja indícios que pessoas da multidão tenham se tornado discípulos do Mestre.

Desta maneira, permite-se pensar o sentido do "ver" de Jesus a partir da perspectiva decolonial, uma vez que Jesus não tinha uma relação pré-estabelecida e formal com a multidão de Mateus 5,1, parecendo retratar a amplitude da mensagem de Jesus e ao mesmo tempo a profundidade do que ele dizia, sem estabelecimento de lugares, tal como quem está para ensinar e quem está para aprender, ou como mestre e discípulos.

A partir deste momento, nosso artigo busca dialogar com as categorias da decolonialidade. $\mathrm{O}$ giro decolonial e as epistemologias do sul podem contribuir para uma pastoral urbana à luz do ver de Jesus e as implicações de seu olhar de discernimento. O escopo é lançar luzes à práxis pastoral no contexto citadino hodierno. Tal percepção, por suposto, nos ajudará a pensar a pastoral urbana no contexto populacional inflacionado, como aquele experimentado por Jesus, com as multidões e por nós hoje, diante de tantos desafios. No contexto de um mundo globalizado e com tendências colonialistas, do ser, saber e poder, a religião também se encontra em crise identitária, buscando seu sentido de ser e agir.

\section{Giro decolonial e epistemologias do sul}

O "movimento de resistência teórico e prático, político e epistemológico, à lógica da modernidade/colonialidade”2, é chamado pelo filósofo porto-riquenho

\footnotetext{
2 Para o sociólogo peruano Aníbal Quijano (1928-2018), a modernidade oculta mecanismos de colonialidade. A utilização da barra inclinada (/) realça o valor disjuntivo entre os termos, ou seja, a 
Nelson Maldonado-Torres de "giro decolonial" (BALLESTRIN, 2013, p. 105). O termo remete a um giro epistemológico capaz de repensar "as formas de produção do saber, os processos de subjetivação e às relações sociais que unem processos de subalternização" (MOJICA; ANDRÉS, 2007, p. 240). O giro decolonial desvela a lógica da colonialidade e a reprodução da matriz colonial do poder para desconectar-se dos efeitos totalitários das subjetividades e categorias do pensamento hegemônico. Mais do que uma opção teórica, o giro decolonial se impõe como uma necessidade ética e política capaz de se desprender da colonização do poder, do ser e do saber.

No mesmo arcabouço teórico-prático está a ideia sugerida por Boaventura de Souza Santos e Maria Paula Meneses: "epistemologias do sul". O "Sul" agregado ao termo "epistemologias" é entendido metaforicamente como um campo de desafios epistêmicos, que procuram reparar os danos historicamente causados por ações colonialistas. Aprender que existe o Sul; ir para ele e a partir dele compõem orientações básicas para pensar e fazer a partir das epistemologias do sul (SANTOS; MENESES, 2010, p. 15-19). O giro decolonial será efetivo se "situarmos a nossa perspectiva epistemológica na experiência social do outro lado da linha, isto é, do Sul global não-imperial, concebido como a metáfora do sofrimento humano sistêmico e injusto" (SANTOS; MENESES, 2010, p. 53) provocado pelo colonialismo". "Epistemologias do sul" é o nome dado à percepção do mundo epistemologicamente diverso.

O "giro decolonial" e "epistemologias do sul” são categorias correlacionadas presentes no fazer decolonial. Na esteira histórica dos estudos pós-colonialistas e desconstrutivistas, a decolonialidade propõe epistemologias críticas às concepções dominantes da modernidade. O deslocamento do locus de enunciação sai dos centros do sistema moderno-colonial para suas margens, para as fronteiras das diferentes histórias locais. Esse giro não significa negar a importância dos saberes ocidentais hegemônicas, mas refletir além deles. Não se trata também de um relativismo cultural e epistêmico. Esses projetos não são lógica opera em quatro domínios: econômico, político, social e epistêmico (QUIJANO, 2016, p. 64). 
universais e abstratos, mas circunscritos nos limites das diferenças coloniais específicas na formação do "sistema-mundo"3 moderno colonial.

Foi no campo epistemológico que a retórica da modernidade ganhou força por produzir e reproduzir discursos e narrativas que justificam a colonialidade. "O paradigma decolonial luta por fomentar a divulgação de outra interpretação que põe em evidência uma visão silenciada dos acontecimentos e mostra os limites de uma ideologia imperial que se apresenta como a verdadeira e única interpretação [...]" (MIGNOLO, 2007, p. 57). A decolonização epistêmica se desvincula dos fundamentos genuínos dos conceitos ocidentais e da acumulação de conhecimento num esforço de reconhecer outros saberes provenientes de culturas de latitudes marginalizadas e de pessoas silenciadas.

Ler o evangelho de Jesus Cristo à luz do pensamento decolonial significa atualizar para o hoje discurso e prática marcados pela subversão. Diferente da anarquia, a subversão prega e executa atos visando à transformação da "ordem estabelecida" (status quo); expressa por meio de ações concretas pensamentos contra hegemônicos (HOUAISS; VILLAR, 2001, p. 2630). As próprias parábolas constantemente utilizadas por Jesus são "instrumentos de combate" contra políticas de dominação. O "ver de Jesus as multidões", do Discurso do Monte (Mt $5,1)$, é provocador porque ele foca com profundidade na existência das "multidões" (óxlos, no grego), isto é, gente sofrida e marginalizada. Para José Castillo, óxlos, nos Evangelhos, faz referência:

[...] à multidão (Mt 4,18; Lc 4,42), na qual são abundantes os doentes e aqueles que eram considerados como endemoninhados (Mt 8,16; LC 4,40-41), isto é, pessoas com "doenças" e "enfermidades" (Mt 8,17; Is 53,4). Trata-se de todos aqueles que "viviam maltratados e desgarrados como ovelhas sem pastor" (Mt 9,36; Mc 6,34). Mais concretamente, eram os pobres, aqueles que não tinham o que comer e aos quais Jesus alimenta (Mc 6, 45; Mt 14,19; Lc 9,11; Jo 6,2.5.22.24), de modo que "vinham de longe" e "em jejum", arriscando "desmaiar pelo caminho" (Mc 7,2; Mt 15,32) (CASTILLO, 2012, p. 142).

\footnotetext{
3 "Sistema-mundo" é uma categoria proposta pelo sociólogo estadunidense Immanuel Wallerstein (1930-2019). Crítico do capitalismo, da ideologia neoliberal e dos mecanismos da globalização, Wallerstein recusa a classificação de Primeiro, Segundo e Terceiro Mundos, argumentando que existe apenas um mundo articulado por um complexo sistema de trocas econômicas - sistema econômico mundial - caracterizado pela polarização entre o acúmulo de capital por uma minoria e o trabalho excessivo da maioria (WALLERSTEIN, 1974).
} 
O ver de Jesus não é inocente, mas consciente da situação existencial de uma multidão maltratada em contraposição à vida tranquila daqueles que compunham o Sinédrio: os "sacerdotes" chefes (a aristocracia sacerdotal), os "anciãos" (a nobreza leiga) e os "escribas". Essa gente detinha o poder na sociedade da época de Jesus. A aristocracia sacerdotal e a nobreza leiga eram consideradas "os primeiros da cidade”, "os poderosos e notáveis do povo”. Já o poder dos escribas residia no saber, visto serem eles os responsáveis pela interpretação da Escritura (CASTILLO, 2012, p. 137). A multidão, plebe, no sentido pejorativo, mais do que quantidade de pessoas, refere-se a pessoas empobrecidas e desprezadas pelos "notáveis".

Além de consciente, o ver de Jesus provoca empatia. Ele se identifica com as dores e as lutas dos rejeitados do seu tempo. No contexto de uma sociedade agrícola, como as sociedades do primeiro século, a desigualdade era notória. De um lado, uma pequena parcela da sociedade gozava da prosperidade e, do outro, uma grande massa do povo sufocada pela escassez de recursos para uma vida digna. Na tensão social entre os extremos, Jesus faz uma opção por peregrinar entre os necessitados. Ele se faz um com o povo. A identificação é tanta que as multidões ficam maravilhadas com as suas palavras e os seus feitos. O seu ensinamento tem autoridade (exousia, no grego), próprio de quem fala do que vive, diferente daqueles que discursam uma coisa e vivem outra completamente diferente (Mt 7, 28-29). O resultado da empatia de Jesus com o empobrecido não poderia ser outro: “[...] grandes multidões o seguiam” (Mt 8,1). "As autoridades temiam atentar contra Jesus, porque sabiam que isso era a mesma coisa que atentar contra o povo, contra a enorme massa dos pobres" (CASTILLO, 2012, p. 143).

Castillo diz que nas relações especificamente humanas, a comunicação simbólica supera a comunicação linguística. Enquanto esta transmite conhecimentos, a simbologia comunica experiências "que comportam prioritariamente uma totalidade de sentido à vida humana" (CASTILLO, 2017, p. 25). A linguagem da teologia cristã, mais do que técnica, tem um forte apelo simbólico. Ela emerge do testemunho na concretude da vida. O ensinar (didaskein, no grego) de Jesus não propõe uma transmissão de conhecimentos teóricos desprendidos da realidade, mas um referencial a partir do seu próprio comportamento. Ver Jesus agir é mais do que suficiente para captar a sua 
mensagem. Os atos simbólicos precedem a linguagem, a ideia, o conhecimento. $O$ convite de Jesus é "vinde e vede" (Jo 1,39).

$O$ ver de Jesus é libertador e decolonial. Ele rompe com os mecanismos de colonização impostos pelo colonizador e assume o lugar do colonizado. A encarnação de Deus não significa apenas que Ele se fez homem, mas que Ele participa plenamente da condição de vida dos humanos e acolhe os seus medos e anseios mais profundos. Jesus introduz o Reino de Deus cujo movimento subversivo inaugurado por sua vida provoca mudanças internas e externas na vida, sobretudo, dos subalternizados. Ao dar consciência da realidade de opressão em que os pobres viviam, Jesus faz críticas às estruturas religiosa e sociopolítica explicitando os diversos mecanismos de dominação. Ele desfere, com veemência, inúmeras críticas em relação às instâncias de opressão e assume a defesa dos oprimidos da sociedade, da política e da religião. O seu lugar de fala é marcado pela autoridade de quem, como os marginalizados do seu tempo, foi perseguido e maltratado.

As vítimas do sistema injusto são os destinatários privilegiados do anúncio do Reino de Deus. Sem prestígio e sem poder, os empobrecidos, cujos direitos são continuamente ameaçados, são agraciados pela salvação/libertação de Deus. Para Jesus, a história humana concreta é o lugar da ação do Pai que ouve o clamor dos seus filhos e faz do Reino algo real. A ação que brota da gratuidade do encontro do Senhor nos necessitados e sofredores busca responder às necessidades concretas da fome, sede, nudez, moradia e outras. Trata-se, pois, de uma ação eficaz que brota da gratuidade do dom do encontro com o Deus do Reino que se identifica com os "povos crucificados" (SOBRINO, 2000, p. 15).

\section{O "ver" decolonial de Jesus}

Vimos como o pensamento decolonial propõe uma epistemologia crítica às concepções dominantes da modernidade assumindo outros lugares de fala, isto é, o giro decolonial. Assumir a virada teórico-prática proposta pela decolonialidade significa repensar a geopolítica do pensamento hegemônico e os seus mecanismos de colonização. A consciência disso possibilita dar vez e voz às multidões de pessoas subalternizadas e empobrecidas que vivem às margens, nas fronteiras, de um sistema injusto. $O$ pensamento fronteiriço que daí advêm traz na raiz das suas 
narrativas não só as dores de quem foi colonizado, mas também, e sobretudo, a riqueza de uma cultura que foi silenciada. Dar voz às multidões subalternizadas, como Jesus fez, significa, ao mesmo tempo, confronto com posicionamentos dominantes e se abrir para outros saberes e novas compreensões do mundo.

"Ver as multidões" como Jesus via, dando a elas o reconhecimento de uma vida digna, incomoda os poderosos, quer dizer, aqueles que se beneficiam da colonização das massas empobrecidas. Jesus desestabiliza as instâncias dominadoras e se torna uma ameaça para os projetos geopolíticos hegemônicos do seu tempo. "O mundo, entendido como sistema injusto, corteja e premia quem não o incomoda, mas desencadeia toda a sua ferocidade contra todos aqueles que com a sua existência são clara denúncia da injustiça do sistema" (MAGGI, 2013, p. 150).

Os "homens do poder" não temem os discípulos de Jesus, mas o povo organizado capaz de tirar a máscara da "pátria" e da "religião" que escondem a paixão pelo poder. "Religião" e "pátria", as duas grandes máscaras usadas por tantos ambiciosos do poder que, em nome de Deus e em nome da nação, buscam "saciar sua insaciável paixão de impor-se, dominar e submeter todos aqueles que caírem sob o alcance de suas pretensões inconfessáveis" (CASTILLO, 2012, p. 149).

Walter Mignolo chama de "ferida colonial" (MIGNOLO, 2007, p. 34) o resultado do "discurso hegemônico que põe em questão a humanidade de todos os que não pertencem ao mesmo locus de enunciação (e a mesma geopolítica de conhecimento) de quem cria os parâmetros de classificação e se dão a si mesmo o direito de classificar e dominar. A ferida colonial possibilita uma "gnose liminar" (MIGNOLO, 2003, p. 103), que é expressão de uma razão subalterna lutando para afirmação dos saberes historicamente subalternizados. Essa gnose ou pensamento liminar é uma reflexão crítica sobre a produção do conhecimento e implica na sua redistribuição geopolítica, até então pautada na colonização epistêmica e na subalternização de todas as formas de saberes, povos e culturas que não estivessem pautadas nos cânones do pensamento dominante. Da ferida colonial emerge a novidade de vida de pessoas, línguas, religiões, conceitos políticos e econômicos, subjetividades e tantas outras expressões que foram negadas.

Novos lugares de enunciação geram novas anunciações. O ministério itinerante de Jesus é um exemplo de como ele rompe com a geopolítica das classes dominantes e escolhe fazer do mundo das minorias o seu lugar de 
proclamação da Boa Nova do Reino de Deus. Ao voltar-se para as minorias judaicas, Jesus acolhe a identidade cultural e religiosa de um povo que foi desprezado pela "cultura urbana helenística tanto quanto a população rural judaica” (THEISSEN; MERZ, 2004, p. 192). Ser chamado de Jesus de Nazaré, o "Galileu" é origem e identificação com a vida de quem foi afastado da Judeia, o lugar dos "homens do poder".

Jesus era um pregador itinerante. O seu itinerário narrado nos evangelhos tem um caráter teológico. "Informações topográficas e cronológicas nos evangelhos muitas vezes fazem parte da estrutura redacional que os evangelistas criaram ao adotar tradições individuais e que é regida por interesses teológicos e historiográficos" (THEISSEN; MERZ, 2004, p. 189). Colocar o centro da atividade pública de Jesus na margem setentrional do Mar da Galileia, como os evangelhos fazem, é muito significativo. As tensões, na Galileia da época do Cristo, entre "gentios e judeus, cidade e campo, ricos e pobres, governantes e governados são de grande significado para a compreensão da pregação de Jesus" (THEISSEN; MERZ, 2004, p. 190) e os critérios teológicos propostos pelos evangelistas.

Para Theissen e Merz, a Galileia do primeiro século era dividida entre: a Alta Galileia, a Baixa Galileia acidentada e a região em volta do Lago da Galileia, com diferentes territórios políticos. Jesus chamou os seus primeiros discípulos em Cafarnaum (Mc 1,16ss), uma região fronteiriça entre a região de Herodes Antipas e a de Felipe. A Galileia era um enclave judeu circundada por cidades-república helenísticas. Na costa do Mar Mediterrâneo "ela fazia fronteira com as cidades de Sídon, Tiro e Ptolemaida; a oeste com a Decápole, uma aliança de cerca de dez cidades-estado helenísticas. No Sul, a Samaria separava toda a região da Judeia. Sebaste, o centro de Samaria, era uma cidade de matiz helenístico" (THEISSEN; MERZ, 2004, p. 185-191).

Jesus, o Galileu, se voltou para as minorias judaicas. O seu discurso e os seus feitos são marcados pelo mundo daqueles que tiveram a sua identidade cultural e religiosa negada. O "agitador" do povo empobrecido encontrou na Galileia e no seu entorno gente disposta a ver os sinais do Reino e a ouvir a sua pregação. $O$ "subversivo" acolhe as dores dos marginalizados, de uma "população abalada em sua identidade pela cultura urbana helenística" (THEISSEN; MERZ, 2004, p. 202).

Quando Jesus vai para Jerusalém, o lugar da "pátria" e da "religião" institucionalizadas e cristalizadas pela sedução do poder, ele se torna vítima das 
tensões sociais, religiosas, econômicas e políticas. A acusação dos "chefes do povo" de que Jesus era um samaritano e endemoninhado (Jo 8,48) não encerra somente o desprezo que os judeus nutriam pelos da Galileia, mas manifesta o medo diante das multidões de Jesus conscientes dos mecanismos da colonização e dispostas a um fazer decolonial capaz de romper os grilhões da opressão.

A escravidão não é tanto condição quanto convicção; não é uma situação, mas atitude. A verdadeira escravidão não é aquela da qual não é possível libertar-se; não é a dos corpos, mas do coração; não é aquela das correntes, mas das convicções (MAGGI, 2013, p. 66).

\section{A pastoral urbana no "ver" de Jesus}

A pastoral na cidade, no mundo urbano, compreende um desafio para a Teologia Pastoral dos tempos atuais, sobretudo pela necessidade de ser inculturada (BRIGHENTI, 2021, p. 207). Para Brighenti, o importante é a "Pastoral Urbana" e não simplesmente o agir pastoral na cidade. Em sentido objetivo, o que se espera é que o urbano seja integralmente pastoral e não apenas pincelado por ações de evangelização aqui ou ali. Trata-se de evangelizar de forma encarnada na realidade levando em consideração os "desafios, estilos de vida, linguagem, símbolos e imaginários próprios" (BRIGHENTI, 2021, p. 207). Para o autor, evangelizar o urbano exige romper com as estruturas epistemológicas do passado.

Na Galileia do primeiro século, Jesus de Nazaré inicia um novo paradigma de ação pastoral, que pode ser considerado, ao nosso ver, "urbano", e, segundo Theissen e Merz, se entende como movimento de renovação que sai para as periferias. "Jesus ativa a fé judaica num Deus misericordioso e gracioso contra outras tendências" (THEISSEN; MERZ, 2004, p. 167).

Jesus, o itinerante, é capaz de perceber as realidades multifacetadas da Galileia. Marcos 1,35ss afirma que de madrugada Jesus deixa Cafarnaum, onde havia realizado inúmeras curas, e foi para um lugar deserto. Simão e os outros discípulos o procuravam ansiosos e quando o encontram disseram a Jesus que "todos o procuravam" (v.37), Jesus, porém, diz aos discípulos que devem ir para outros lugares, às aldeias vizinhas, para pregar, pois foi para isso que ele saiu. Destarte, entendemos o movimento pastoral "urbano" de Jesus como 
compromisso de ir aos povoados, cidades e pessoas. Não há, de forma explícita nos Evangelhos, relatos de Jesus agindo apenas e exclusivamente nas cidades, mas passando por elas, caminhando em direção a Jerusalém, passando por Tiro, Sidônia e a Decápole (Mc 7,24 e 11,1). A pastoral de Jesus não é exclusivamente urbana, mas capaz de congregar as pessoas, atraindo-as com a palavra, celebrada com o pão, capaz de saciar a fome (Mt 14, 13-21; Mc 6,31-44; Lc 9,10-17 e Jo 6,5-15).

Deste modo, Jesus renova o modelo de discipulado itinerante, no qual inclui o convite ao discipulado. Esta renovação missionária, "em saída” possibilitou que seu evangelho, a Boa Nova do Reino, penetrasse os mais profundos rincões da Galileia e Síria (Mc 1,28; Mt 4,23-25; 4,24; LC 4,37; 7,17). A missão de Jesus se assemelha a de João, o Batista, que percorria toda a região do Jordão "proclamando um batismo de arrependimento para a remissão dos pecados" (LC 3,3b). Jesus, porém, diz: "Cumpriu-se o tempo e o Reino de Deus está próximo. Arrependei-vos e crede no Evangelho" (Mc 1,15).

A ação missionária de Jesus está estritamente ligada a seu "ver decolonial", o modo mesmo de Jesus discernir as realidades e pessoas que o circundam. A partir do ver decolonial de Jesus supomos nesta reflexão final duas perspectivas: a primeira, da saída, da ação missionária por parte do (da) discípulo/discípula de Jesus. No ver de Jesus percebe-se a natureza de sua missão. Jesus é o itinerante do Pai, o enviado para a missão, desta natureza deriva a missão de todo seu discipulado, ontem e hoje. A segunda é do ver de Jesus as pessoas com as quais ele se encontra na missão. Trata-se de perceber o dinamismo do ver decolonial de Jesus no qual irrompe a misericórdia, a compaixão para com aquele que é sujeito de seu olhar e não simplesmente objeto. Jesus vê de forma discernente, percebendo as pessoas em sua integridade e não naquilo que elas significam ou expressam. O ver decolonial de Jesus perscruta o âmago das pessoas e suas mais implícitas deficiências, faltas e debilidades.

No texto evangélico de Mateus, no início do discurso da montanha (Mt 5,1), Jesus se relaciona com as multidões, ele vai ao encontro delas a fim de ensiná-las. Em Mateus 4,23-25, perícope sumária anterior que introduz Mateus 5, o narrador de Mateus afirma que "Jesus percorria toda a Galileia, ensinando em suas sinagogas, pregando o Evangelho do Reino e curando toda e qualquer doença ou enfermidade do povo". Mateus afirma que a fama de Jesus se espalhava por toda Síria, de modo que de lá também Ihes traziam enfermos para serem curados. Nota- 
se, na narratologia dos Evangelhos, que a ação pastoral de Jesus se espalha, atingindo diversas realidades, o ensino e a taumaturgia de Jesus vão além das fronteiras de Israel, e não se atém ao nacionalismo. A ação ad gentes explícita no Evangelho pode ser entendida pelo modo de ver de Jesus que paulatinamente vai sendo ampliada, das ovelhas da casa de Israel para os pagãos. Em Marcos 6,32, Jesus segue de barco para uma região deserta, "afastada", segundo o narrador. Em Marcos 6,34, por ocasião da multiplicação dos pães, Jesus se encontra com grande multidão e as vê como ovelhas sem pastor. Salvaguardando as devidas proporções entre a realidade dos evangelhos e a nossa hoje, do contexto de cidades e metrópoles, pode-se observar que o termo "multidão" ou "multidões" relaciona-se ao conceito urbano, como coletivo de pessoas que estão juntas, em coletividade.

É valido ressaltar que os relatos evangélicos apontam para a práxis de Jesus em um horizonte anterior à escrita. Nossa questão é perceber que o movimento pastoral de Jesus pode ter influenciado decisivamente à escrita e notar que o narrador amplia, com a sua redação, o horizonte pastoral de Jesus. O narrador, que está há décadas do evento e do movimento de Jesus, está inserido em uma comunidade coletiva, que já fez o movimento do discipulado. É possível que exista uma semelhança entre os fatos narrados e o contexto de Jesus, que atraia para junto de si homens e mulheres, pois sua pregação, ensino e taumaturgia despertavam em muitos o desejo de ouvi-lo e de segui-lo (Mc 10,52).

O ver decolonial de Jesus irrompe os limites da casa de Israel, indo alémfronteiras e é capaz de alcançar as mais profundas e presentes condições e situações antropológicas, os anseios e necessidades dos homens e das mulheres. A ação pastoral de Jesus inculturou-se às realidades diversas, partindo da realidade pequena de Nazaré, percorreu os mais diversos espaços ao derredor das margens do Mar da Galileia, Cafarnaum sobremaneira (Mc 1,21-39), atingindo, assim, de forma crítica, a capital religiosa, Jerusalém.

A frente da ação pastoral “urbana” de Jesus não se vê inarredável, nem autocentrada, mas em saída, em verdadeira itinerância popular. Jesus não está fixo em uma sinagoga ou no Templo de Jerusalém. O espaço sagrado de seu ministério é o caminho do mar, o mundo da Galileia, dos pobres e pecadores, os excluídos e aqueles que estão além de Israel (Mc 7,24-29). Este é um primeiro signo hermenêutico para a pastoral urbana no horizonte atual. Quanto mais os 
discípulos de Jesus estiverem em saída, à luz da ação dele, mais facilmente o Evangelho do Reino de Deus atingirá e permeará as diversas realidades, capilarizando a mensagem do Nazareno. Para tal, faz-se oportuno e urgente ultrapassar o esquema colonial, como de igreja, como lugar quase exclusivo para o qual as pessoas cristãs se dirigem para orar, reunir e celebrar.

O desafio para a pastoral urbana hodierna consiste em ultrapassar a experiência da comunidade eclesial ritualizada ou cultual, a fim de que se possa emergir um cristianismo vital no tecido integral da sociedade. Em busca da superação do assistencialismo emergencial das igrejas, a pastoral é interpelada a assumir o protagonismo do enfrentamento das injustiças e mazelas que atingem e assolam a sociedade, sobretudo os menos favorecidos e pobres. Há, neste sentido, o desejo de que o Reino de Deus aconteça nas estruturas da sociedade e que a luz do Evangelho possa iluminar as relações humanas.

Nesta perspectiva, há como pensar, discernir e colocar em ação o novo paradigma de igrejas e comunidades, uma realidade capilarizada, descentrada, a partir da evangelização de cada fiel, de cada membro que se constitui uma porção do Povo de Deus, a Igreja. Cada cristão é um agente de evangelização, um anunciador do Evangelho da Vida. Hoje, veem-se oportunas a revitalização da vida dos cristãos batizados e a multiplicação de "pequenas comunidades" (DAp 178180) de discípulos missionários de Jesus Cristo. Em sentido amplo, os cristãos veem-se chamados a pensar seu agir no mundo, comprometidos com o Evangelho de Jesus, a fim de iluminar as relações humanas, políticas, sociais, midiáticas etc. Há no agir cristão um comprometimento com a história humana, ser "sal da terra" e "luz do mundo" (Mt 7, 13-16).

O ver decolonial de Jesus, no percurso da missão, da saída de si mesmo e das situações confortáveis, nos leva a pensar o modo como ele vê, como ele discerne as situações e as pessoas vulneráveis ou não. O olhar decolonial de Jesus avança para o mais profundo, para a não acepção (distinção) de pessoas, para o não juízo. Assim, fenomenologicamente dizendo, o olhar de Jesus em primeira instância não coloca ninguém no tribunal, na inquisição. Os doentes e necessitados têm predileção ao alcance imediato do olhar de Jesus, isso não significa que os sãos e "santos" não seriam olhados por ele. Até os mais justos, aqueles que observavam integralmente a Lei mosaica traziam em seus corações a falta e Jesus 
era capaz de vê-las, discerni-las e percebê-las, pois seu ato de ver não estava colonizado pela pressa, pelo descaso e insensibilidade.

Na perspectiva do ver decolonial de Jesus, podemos ler o relato exemplar do Segundo Evangelho do encontro entre Jesus e o homem rico (Mc 10,17-22). Marcos destaca que Jesus "ao retomar ao seu caminho, alguém correu e ajoelhouse diante dele perguntando: 'Bom mestre, que farei para herdar a vida eterna?'” (v. 17). Em seguinte, a narrativa evidencia Jesus corrigindo o homem: "Por que me chamas bom? Ninguém é bom senão só Deus" (v.18) e lhe pergunta se conhece os mandamentos de Deus. Jesus Ihe faz memória dos seis mandamentos do Decálogo, a fim de questionar sua fidelidade (v. 19). O homem lhe responde: "Mestre, tudo isso eu tenho guardado desde minha juventude" (v. 20). Em seguida, no clímax da narrativa, Marcos ressalta que "fitando-o, Jesus o amou e disse: 'Uma só coisa te falta: vai, vende o que tens, dá aos pobres e terás um tesouro no céu. Depois, vem e segue-me" (v. 21). A perícope encerra com o homem saindo pesaroso, pois possuía muitas riquezas e não conseguia se desfazer delas (v. 22). A leitura desta passagem bíblica, à luz da pastoral urbana de Jesus, nos leva a perceber a existência da injustiça e da desigualdade social: a existência dos pobres e a incapacidade de este homem pensar neles e ser capaz de partilhar com eles sua riqueza. Infelizmente, esta situação perdura até os dias de hoje, sobretudo na práxis desencarnada de muitos cristãos, que não se veem preocupados ou comprometidos com as transformações da sociedade injusta.

No clímax da narrativa, o narrador põe em relevo a catequese do olhar de Jesus. Em primeiro plano, no ato mesmo do ver de Jesus, expresso pelo verbo “fitar", ver com intensidade e em seguida, amá-lo. Em terceiro e último momento, desta cena Jesus tira uma conclusão: "olhando em torno, disse a seus discípulos: 'Como é difícil a quem tem riquezas entrar no Reino de Deus"'.

Nesta perícope, nota-se que o ver de Jesus é amoroso e capaz de encontrar no ser humano sua falta, ou seja, Jesus é capaz de ver que o excesso de coisas e o apego aos bens materiais se tornam empecilho para o discipulado. Assim, não apenas os pobres e pecadores eram sujeitos ao ver de Jesus, mas também os ricos, porque na verdade eram pobres, pois estavam inábeis para o caminho de Jesus, pois o apego material os impedia de uma profunda experiência de renúncia (Mc 10,29). Embora a conclusão de Jesus possa parecer um juízo a respeito da incapacidade daquele homem de segui-lo, pode ser entendido apenas como 
discernimento das condições de possibilidade daqueles que desejam segui-lo. Assim, pode-se compreender o sentido do ver de Jesus na escolha dos primeiros discípulos em Marcos (1,16.19; 2,14).

A partir desta observação sobre o ver de Jesus, o ver de pastor (Mc 6,34), o ver daquele que escolhe as pessoas para segui-lo, podemos pensar a pastoral urbana como lugar de ebulição de infinitas imagens e sentimos que podem ser vistos: sofrimento, dor, morte, pobreza, fome e inúmeras misérias, que dia após dia se sobrepõem umas às outras. É um mundo de contradições, de injustiças, onde muitas vezes se erguem os arautos do individualismo, da ganância, do descaso, da insensibilidade, do obscurantismo e das colonizações, seguidas de suas consequências mais nefastas: a violência e o atual "cancelamento", como nova expressão para dizer de um ostracismo para o qual as pessoas podem estar condenadas por causa de suas opções ou por suas decisões, sejam pensadas ou não.

O ver decolonial de Jesus permite ao olhar da Igreja hoje perscrutar as realidades nas quais os fiéis cristãos estão inseridos. A análise crítica da realidade coaduna com o ver crítico, discernente de Jesus de Nazaré. Para Jesus, a realidade na qual alguém está inserido é o lugar ideal para a missão. Para as Igrejas hoje, o mundo, a cidade, as metrópoles, nossas mais diversas realidades são espaços imprescindíveis para o anúncio do Evangelho, para o convite ao seguimento de Jesus e para a ação pastoral aberta, includente, transformadora e capaz de possibilitar às pessoas, aos cristãos, verem a gravidade da missão que lhes é confiada pelo batismo e de serem capazes de ver o rosto das pessoas como rostos de irmãos e irmãs.

Portanto, as comunidades cristãs são desafiadas a se tornarem realidade solidária, e, simultaneamente, estão chamadas a ver e a ouvir os excluídos, marginalizados e empobrecidos. Os cristãos são convidados a se tornarem próximos das realidades humanas ameaçadas. Em Lucas 10, 25-37, encontramos a narrativa parabólica do samaritano, que se fez próximo do homem tomado em assalto. O samaritano "viu" o moribundo, compadeceu-se dele e passou a servi-lo cuidando de suas feridas e, ainda, levou-o para uma hospedaria arcando com todas as despesas. 


\section{Considerações finais}

A multidão ou as multidões não são para a ação pastoral de Jesus uma dificuldade, mas uma condição de possibilidade. Jesus é o pastor acolhedor, que levanta as pessoas e as cura (Mc 1,29-31). Trata-se de um verdadeiro taumaturgo que continua a realizar a obra soteriológica de Deus, na condição de Filho (Mc 1,1; 15,39). Percebeu-se neste artigo que Jesus tem predileção por uma missão de peregrino, itinerante que vai pela Galileia anunciando o Evangelho ( $M c$ 1,14-15). Jesus é também um mestre em ensinamentos novos e provocadores.

Através da análise de algumas passagens bíblicas, de Marcos e Mateus, sobremaneira o início do discurso da Montanha (Mt 5,1) evidenciou-se que Jesus realiza uma pastoral urbana, com pessoas que estão em realidades distintas, mas sempre juntas. Buscou-se entender a ação de Jesus não "nas cidades", mas em passagem por elas, assim aconteceu em Tiro e Sidônia ( $M c$ 7,24) e Jerusalém (Mc 11,1). Jesus tem contato com as pessoas das cidades, faz milagres em suas vidas, mantém uma relação dialógica com elas. Não há nos Evangelhos uma ação pastoral de Jesus exclusivamente citadina, mas com pessoas, sejam dos campos, sejam das cidades pelas quais ele percorreu.

A leitura decolonial do ver de Jesus nos permite perguntar a respeito do ponto de convergência com o nosso olhar de cristãos. Somos capazes de ver o mundo e as pessoas com o mesmo olhar de Jesus? Ter uma visão discernente, avaliadora, capaz de alçar realidades distantes é o desafio de toda comunidade cristã e de todo cristão hoje. Sobretudo porque estamos inseridos na sociedade que vive a cegueira da negação do outro, do próximo, daquele que nomeamos como irmão.

A decolonialidade do ver de Jesus permitiu-lhe ir além das aparências e ser capaz de penetrar os sentimentos e vazios existenciais das pessoas a sua volta, com os quais pelo caminho ele ia se encontrando. Neste sentido, a primeira percepção da decolonialidade do olhar, do ver de Jesus, está na capacidade de sair para as periferias, sejam aquelas sociais, sejam as existenciais. No caminho para Jerusalém, Jesus se deparou com inúmeras situações, algumas descritas nos evangelhos.

O ver decolonial de Jesus é caracterizado ainda pela capacidade de discernir os contextos e situações vitais, indo ao mais profundo, provocando rupturas com 
as instâncias de dominação. Na multiplicação dos pães narrada por Marcos, podese observar um Jesus sensível, discernente, capaz de se colocar no lugar das pessoas, por isso pleno de compaixão. Ele vê a multidão, sua pastoral urbana, e sente compaixão, pois estavam como ovelhas sem pastor.

Os dois aspectos do ver decolonial de Jesus, sempre em saída para as periferias e capaz de misericórdia, instiga-nos a pensar o ver dos cristãos hoje. Percebemos nitidamente que a ação pastoral do Papa Francisco, por exemplo, está totalmente embebida destes dois aspectos, da missão e da misericórdia. $O$ bispo de Roma é um verdadeiro pastor, peregrino, pobre e sensível. Francisco é hoje uma figura moral capaz de atrair cristãos e não cristãos e desperta na consciência da humanidade o desejo de um olhar mais profundo e maduro.

Enfim, este artigo pretendeu despertar-nos para o ver de Jesus, capacitado à saída e à vivência da compaixão, do compadecimento. A dinâmica decolonial do ver de Jesus tem o poder de despertar-nos à autoconsciência de nosso próprio olhar: em saída e compassivo.

\section{Referências}

BALLESTRIN, L. América Latina e o giro decolonial. Revista Brasileira de Ciência Política, Brasília, n. 11, maio/ago. 2013.

BRIGHENTI, A. Teologia Pastoral: a inteligência da ação evangelizadora. Petrópolis: Vozes, 2021.

CASTILLO, J. A humanidade de Jesus. Petrópolis: Vozes, 2017.

CASTILLO, J. Espiritualidade para insatisfeitos. São Paulo, Paulus, 2012.

CELAM. Documento de Aparecida, Texto conclusivo da V Conferência do Episcopado latino-americano e do Caribe. São Paulo: CNBB, Paulus, Paulinas, 2007.

JEREMIAS, J. O Sermão da Montanha. São Paulo: Ed. Paulinas, 1976.

HOUAISS, A.; VILLAR, M. S. Dicionário Hoauiss da língua portuguesa. Rio de Janeiro: Objetiva, 2001.

INCHAUSTI, R. Ortodoxia subversiva: foras da lei, revolucionários e outros cristãos disfarçados. São Paulo: É Realizações, 2021. 
MIGNOLO, W. Histórias locais/Projetos globais: colonialidade, saberes subalternos e pensamento liminar. Belo Horizonte: Ed. UFMG, 2003.

MIGNOLO, W. La idea de América Latina. La herida colonial y la opción decolonial. Barcelona: Gedisa, 2007.

MOJICA, D. A. S. Reseña de "El giro decolonial: reflexiones para una diversidad epistémica más allá del capitalismo global” de Santiago Castro-Gómez y Ramón Grosfoguel (Eds.) Nómadas (Col), n. 27, p. 239-242, 2007. Disponível em: <http://www.redalyc.org/articulo.oa?id=105116595019>. Acesso em: 26 fev. 2021.

QUIJANO, A. Colonialidad y modernidad-racionalidad. In: PALERMO, Z.; QUINTERO, P. (Coord.). Aníbal Quijano: textos de fundación. Buenos Aires: Editorial: Ediciones del Signo, 2016.

SANTOS, B. S.; MENESES, M. P. (Orgs.). Epistemologias do sul. São Paulo: Cortez, 2010.

SOBRINO, J. A fé em Jesus Cristo: ensaio a partir das vítimas. Petrópolis: Vozes, 2000.

THEISSEN, G.; MERZ, A. O Jesus histórico: um manual. 2.ed. São Paulo: Loyola, 2004.

WALLERSTEIN, I. The Modern World System. New York: Academic Press, 1974.

RECEBIDO: 22/05/2021

RECEIVED: 05/22/2021

APROVADO: 08/09/2021

APPROVED: 09/08/2021 